\title{
THE ASSESSMENT OF THE RESIDUAL STRESSES INFLUENCE ON GENERATION OF THE INFRINGEMENT IN SHAPE-COMPLEX SUPPORTING MEMBERS
}

\author{
PÁSTOR Miroslav ${ }^{1}$, ČARÁK Peter ${ }^{1}$, GÖMÖRY Imrich ${ }^{1}$ \\ ${ }^{1}$ Technical University of Košice, Faculty of Mechanical Engineering, Department of Applied Mechanic and \\ Mechanical Engineering, Letná 9, 04200 Košice, Slovakia, e mail : miroslav.pastor@tuke.sk
}

\begin{abstract}
The aim of the paper is to assess the effect of residual stresses on the damage of the slide bearer. To quantify the residual stresses, the drilling method using SINT MTS 3000 drilling machine was chosen. The tensometric rosette application areas were determined based on the analysis of the results obtained by numerical modeling using the finite element method. Experimental measurement was performed on one unused slide bearer and on the other one, which during its present operation had completed about $9.10^{6}$ cycles. At the end of the paper, the analysis of the measured residual stress values in chosen locations is presented.
\end{abstract}

KEYWORDS: Residual stresses, numerical modeling, Photostress.

\section{Introduction}

For the safe operation of a bogie, it is necessary that it includes elastic elements to provide suspension in the vertical, longitudinal and transverse directions. The greatest demands are placed on the vertical suspension, which is often designed in such a way as to provide transverse and longitudinal suspension as well. One of the bogie elements (Fig. 1) which serves to dampen oscillation of the bogie superstructure is the slide bearer. It is a mechanism consisting of several parts with the top part mounted on two elastic members, which moves in the line with the prescribed clearances (up to $1 \mathrm{~mm}$ ). The cut view of this type of the slide bearer is shown in Fig. 2.

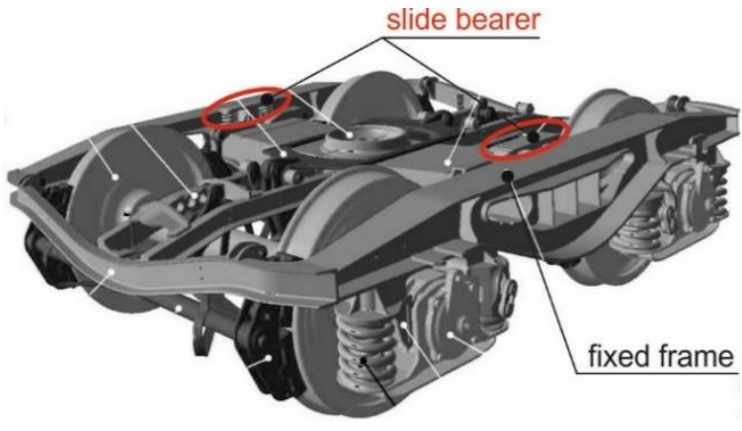

Fig. 1 View of the bogie [1].

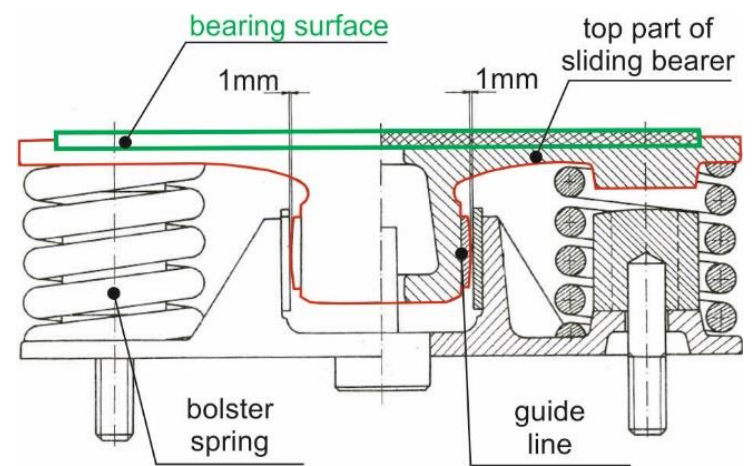

Fig. 2 Cut of the slide bearer.

It was found that after a certain period in operation there was excessive friction of the rigid part and the guiding bore of the slide bearer in the examined bogie, which subsequently affected the damping effect of the slide bearer. For these reasons, a new constructional design of the slide bearer was proposed by means of an anchor belt attached to the fixed frame of the bogie 
with four screws [2]. Fig. 3 shows schematic view of the attachment of the slide bearer to the rigid frame via anchoring belt.

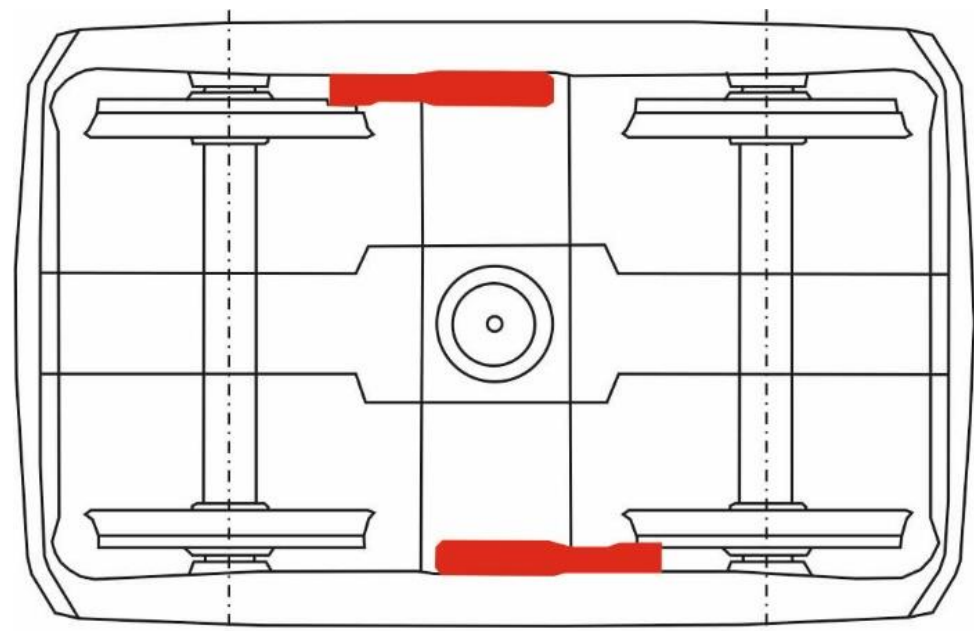

Fig. 3 Schematic view of the attachment of the slide bearer to the rigid frame via anchoring belt.

After the test operation of the newly designed slide bearer, a horizontal displacement of the anchor belt was identified, which also caused undesirable friction in the guide line. The most likely cause can be loosening of the screw connection due to dynamic stress. In order to prevent this displacement, roughening of the contact surfaces in the area A, B of the tightening of screws - variant 1 (Fig. 4a) was suggested. Fig. 4b shows the grooves formed on the anchor belt of the slide bearer.

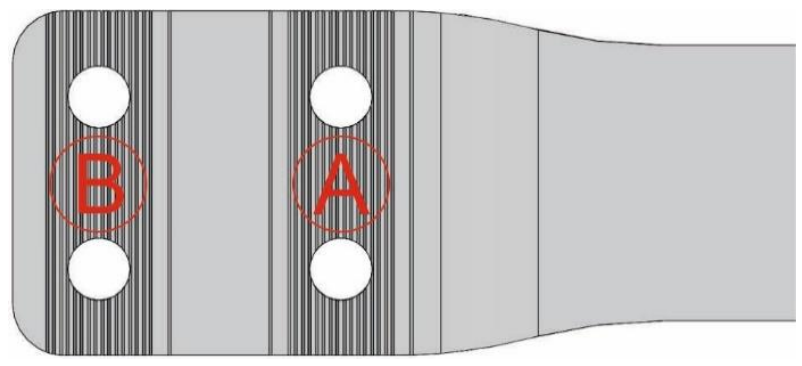

a)

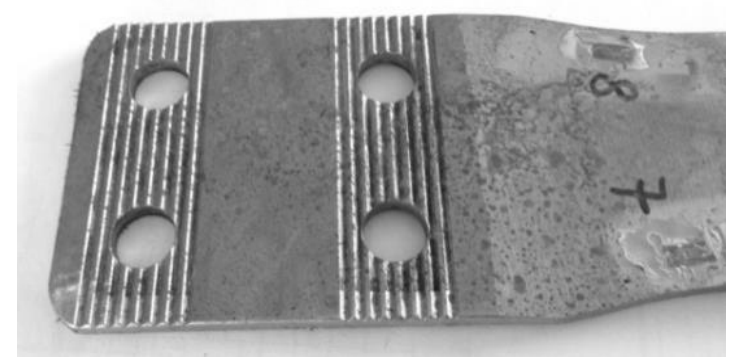

b)

Fig. 4 a) View of areas (A, B) of roughening of the contact surface on the anchor belt,

b) anchoring belt with grooves - variant 1 .

This design proved to be inappropriate since the screw holes themselves may be considered as concentrators causing elevated stresses in their surroundings. Creating "sharp" grooves (notches) increased the level of the stresses. It should be noted that already when designing the concentrator (its shape, size, position, etc.), it has to be borne in mind that stresses are not only caused by operating loads but also by material processing technology, assembly and manufacturing uncertainties as well as residual stresses from production. Despite the fact that $51 \mathrm{CrV} 4+$ QT with a higher characteristic stress $(\mathrm{Re}=1200 \mathrm{MPa})$ was used for the production of the anchor belt, there was a fracture in area A (Fig. 5). The mechanical properties of material 51CrV4 + QT are shown in Tab. 1 [2]. 
Table 1. Mechanical properties of material 51CrV4 + QT [3].

\begin{tabular}{cccc}
\hline $\begin{array}{c}\text { Young's modulus E } \\
{[\mathrm{MPa}]}\end{array}$ & $\begin{array}{c}\text { Shear modulus G } \\
{[\mathrm{MPa}]}\end{array}$ & Yield Strength Re & Tensile Strength Rm \\
210000 & 80000 & {$[\mathrm{MPa}]$} & {$[\mathrm{MPa}]$} \\
\hline
\end{tabular}

As it is obvious from Fig. 5, the fracture occurred in the "front" pair of holes. Assuming that the screw connection forms a firm connection (all bolts are equally tightened), the most likely cause of the fracture in the area of the front pair of screws was the effect of the operating load.

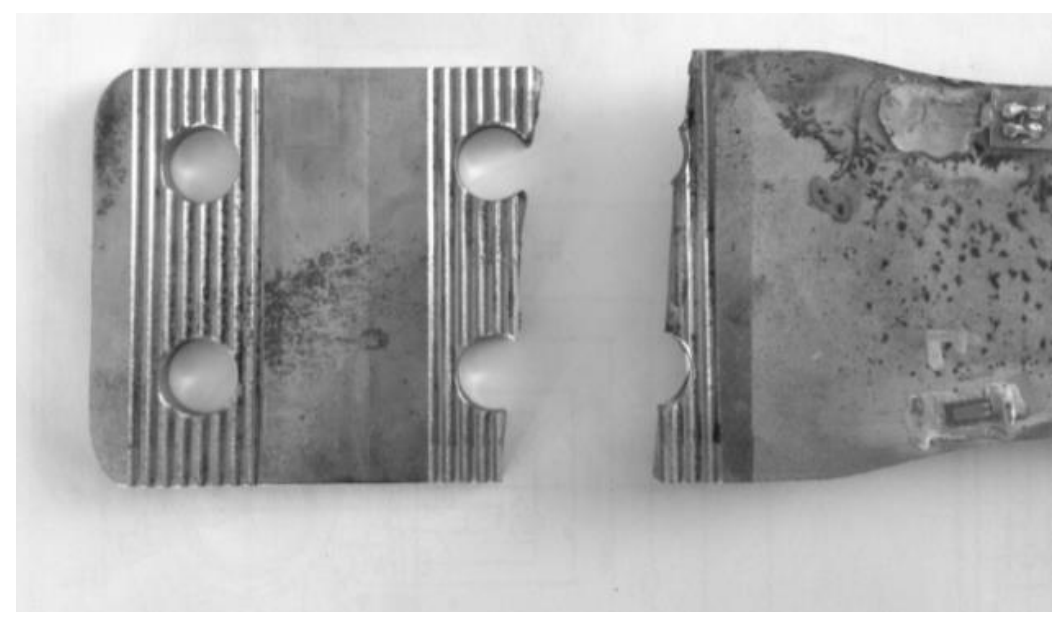

Fig. 5 View of the broken anchor belt - variant 1

On the basis of the facts, a modification of the original design solution was subsequently implemented, which involved the formation of grooves just around the rear screws (area B) variant 2 (Fig. 6). After the test operation of the newly designed slide bearer (approx. 9.106 cycles) it did not break.

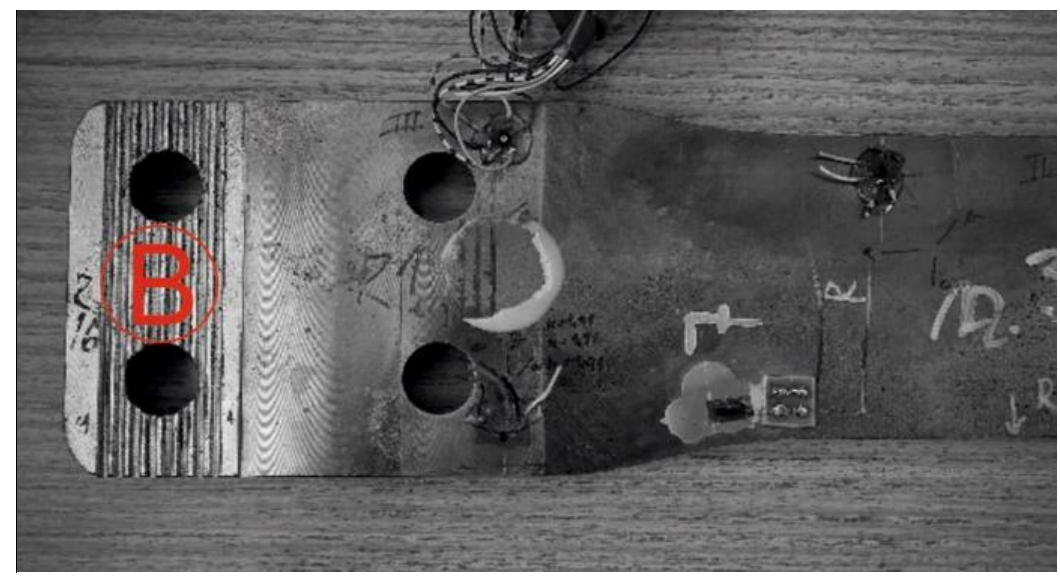

Fig. 6 Anchor belt with formed grooves around the rear screws (area B) - variant 2

Although in variant 2 the anchor belt did not break, the operator raised the requirement to determine the residual stress levels in the anchor belt materials to assess their impact on the life of the slide bearer. To experimentally determine residual stresses, two slide bearers were provided - one new (not used) and the other one after its test operation (about 9.106 cycles). 


\section{Determination of the location for residual stress measurement by numerical modeling using finite element method}

When selecting places for measuring residual stresses not only the shape of the anchor belt, but also technical possibilities of applying the strain gauge and the attachment of the measuring instrument were taken into account. In order to detect areas with elevated stress levels, numerical modeling was performed using the finite element method. Fig. 7 shows a mashed model of the anchor belt with boundary conditions. In the place of the openings, the slide bearer was firmly attached and the load was induced by defining the maximum displacement (vertical displacement) of the upper part of the slide corresponding to the value of $14 \mathrm{~mm}$ (data from the operator). The field of the reduced stresses at the static load defined by the prescribed maximum deflection is shown in Fig. 8. As is apparent from Fig 8, the greatest values of the reduced stresses are around the openings of the front pair of screws (area A).

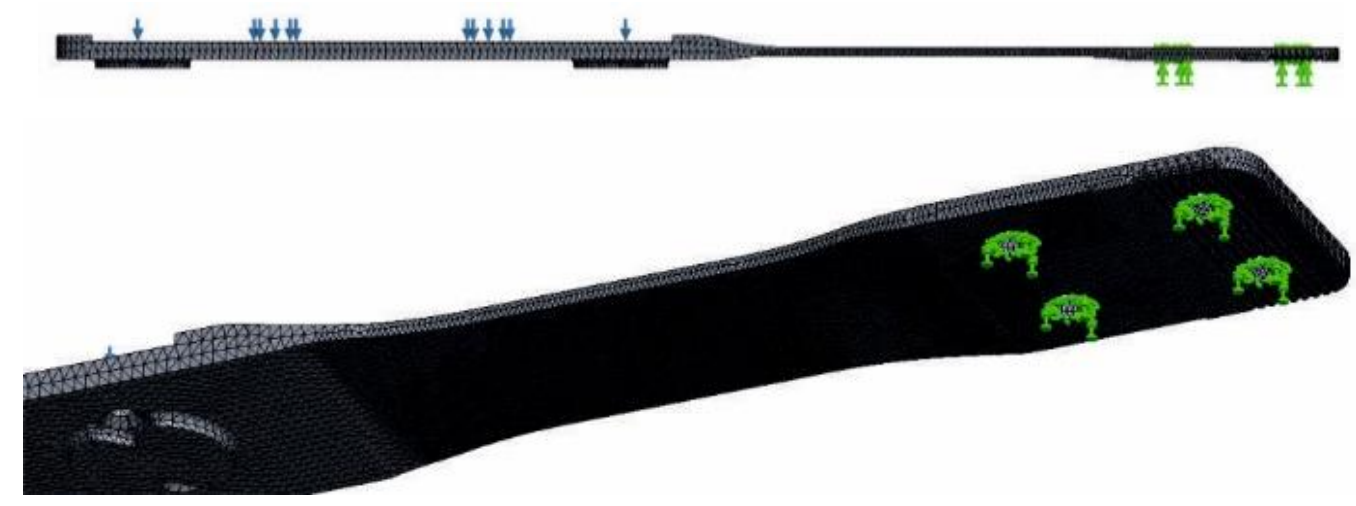

Fig. 7 Mashed anchor belt model with boundary conditions.

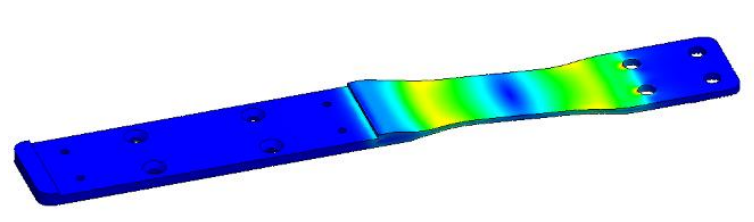

a)

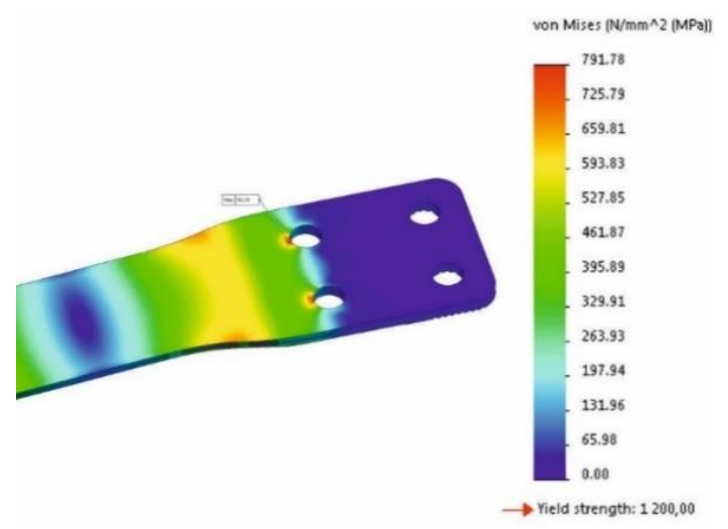

b)

Fig. 8 Fields of von Mises stresses at a defined load a) full field, b) detail.

Based on the results of numerical modeling were selected from the dimensions of the strain gauge rosettes and the handling space for the measurement device holding places for application of tensometric rosettes. Fig. 9 gives localization of places I and II for the application of strain gauge rosettes on the unused anchor belt of the slide bearer - variant 2. Places designated as III and IV were chosen for the used slide bearer (place III corresponds to I and place IV corresponds to II). 


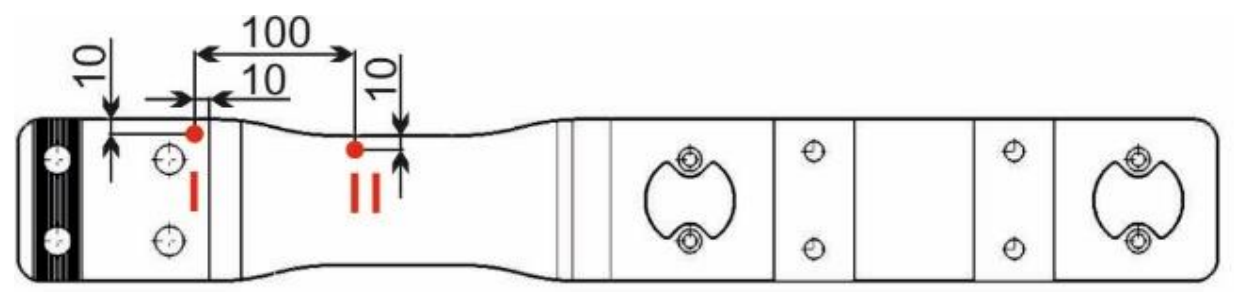

Fig. 9 Localization of tensometric rosettes on the anchor belt - variant 2.

\section{Experimental determination of residual stresses}

For the determination of residual stresses on structures and machine components, drilling methods are most commonly used in practice. The basic principle is to determine the change in strain in the area drilled through the hole into the sample in which residual stresses occur. $[4,5,6,7]$. The change of the released deformation is registered by means of tensometric rosettes applied around the drilled hole. The procedure for measuring and evaluating the released strains is described in detail in standard ASTM E837-13a [8]. At present some authors are dedicated to improvements of the hole-drilling test method to increase the accuracy in determining residual stresses in polymeric materials [9]. Various types of drilling devices are used to determine residual stresses. The authors of the article have a wealth of experience with the use of SINT MTS 3000, SINT MTS 3000 Ring-Core [10] and RS-200 devices to solve practical tasks $[11,12]$.

The drilling of holes has been accomplished by equipment SINT MTS 3000 (Fig. 10) with using strain gauge rosettes type 1-RY61-1.5/120S, $\mathrm{k}$-factor $\left(\mathrm{k}_{\mathrm{a}}=\mathrm{k}_{\mathrm{b}}=\mathrm{k}_{\mathrm{c}}=1.94\right)$, $\mathrm{SN} 812082791$.

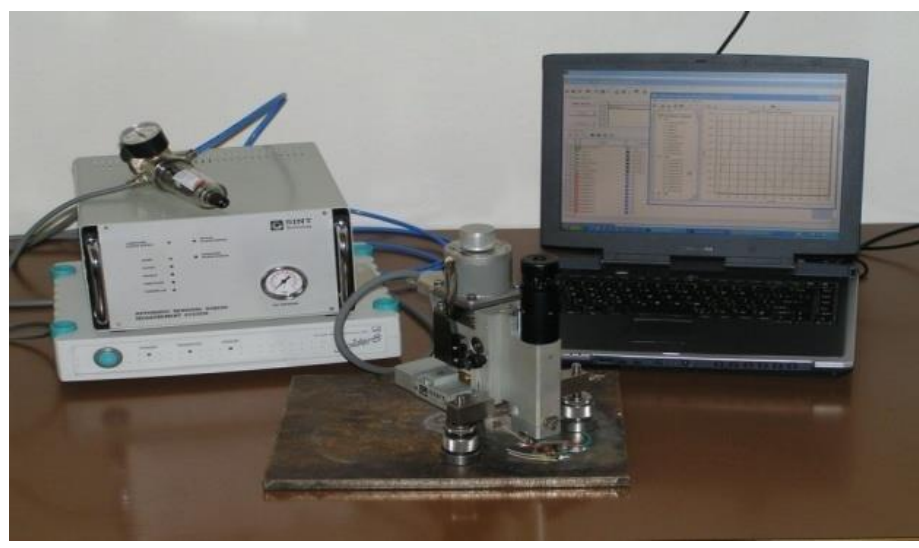

Fig. 10 Measuring device SINT MTS 3000 [10].

The location and orientation of the strain-gauges is illustrated in Fig. 11. The grid direction a (see Fig. 11) was chosen in parallel with the longitudinal axis of the slide bearer. In order to achieve a clearer comparison of the values of stresses and their directions in the measuring points, the same procedure was applied to all the rosettes. A view of the drilling and centering process of the drilling device is shown in Fig. 12.

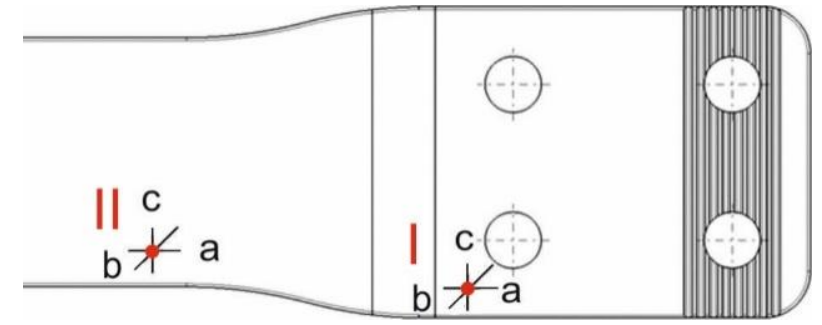

Fig. 11 Orientation of measuring grids of tensometric rosettes. 


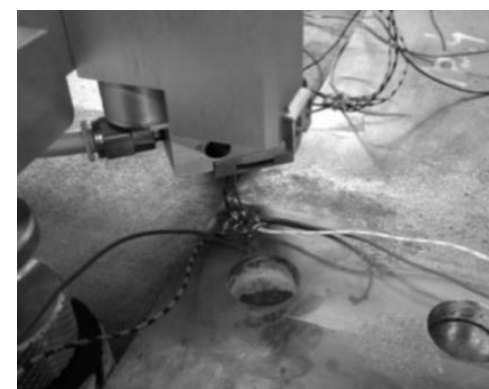

a)

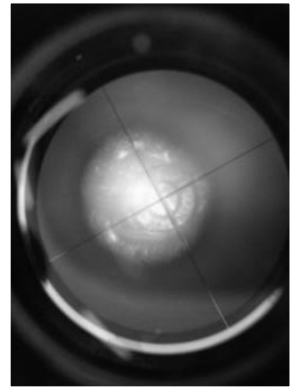

b)

Fig. 12 a) Drilling process at location I b) centering.

Process of hole drilling was accomplished in twenty steps by $0.1 \mathrm{~mm}$ and resulting hole depth $2.0 \mathrm{~mm}$. The diameter of hole was $1.6 \mathrm{~mm}$. The released strains have been registered in each step of measurement by strain-gauge equipment SPIDER 8. In Tab. 2 are given the magnitudes of residual stresses and their directions computed by program MTS3000 Restan from the measured released strains according to ASTM E 837-13a. Angle $\alpha$ represents declinations of $\sigma_{\max }$ from the axis of the slide bearer. For illustration, principal residual stresses in places I and II are shown in Fig. 13.

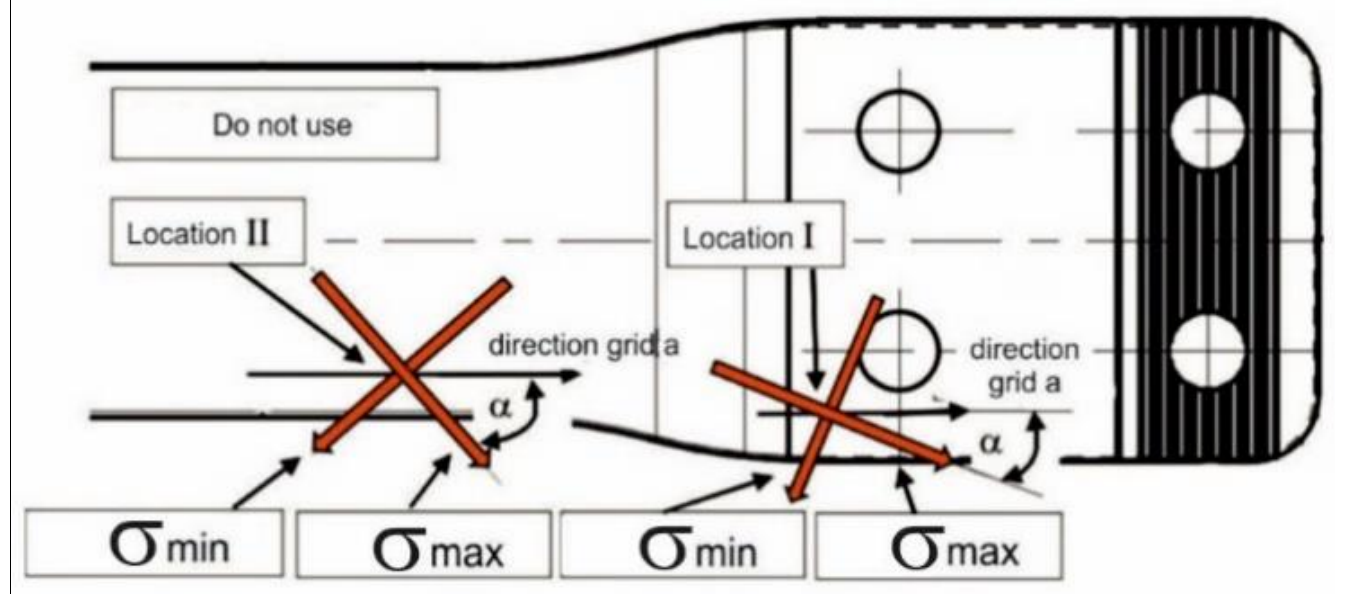

Fig. 13 Magnitudes and directions of principal residual stresses at location I and II.

Table 2. Magnitudes of principal residual stresses and their directions determined according to ASTM E 837-13a.

\begin{tabular}{ccccc}
\hline Slide bearer & Location & $\sigma_{\min }[\mathrm{MPa}]$ & $\sigma_{\max }[\mathrm{MPa}]$ & $\alpha\left[^{\circ}\right]$ \\
not used & I & $-302,07$ & $-234,31$ & $-22,79$ \\
& II & $-341,58$ & $-255,19$ & $-49,70$ \\
after test & III & $-273,07$ & $-203,83$ & $-57,54$ \\
operation & IV & $-266,67$ & $-220,42$ & $-37,83$ \\
\hline
\end{tabular}

Negative residual stress values were found in all measuring points using the drilling method. This finding corresponds to the fact that the anchor belt was machined by forging, as was confirmed by the manufacturer. Forging is often used in practice to induce pressure stresses that can be considered more favourable in terms of stress. On the basis of the comparison of residual stress values on a new and already used slide bearer, it can be concluded that the values were slightly lower on the used slide bearer. 


\section{Quantification of residual stress using Photostress method}

Due to the fact that in the authors workplace we have extensive experience with the use of experimental methods to solve problems for practice $[13,14,15]$, we decided to verify the results of experimental measurements for the determination of residual stress obtained by the drilling method using the Photostress optical method. It should be noted that the use of optical methods (DIC, ESPI) in combination with drilling is addressed by several authors [16,17]. The advantage of these non-contact methods is, among other things, the possibility of full-body analysis in the area analysed [18].

PhotoStress is a full-field stress and strain analysis method that can be used under various live load conditions [19]. It's suitable for residual stress analysis, assembly stress inspection and fatigue tests. A variety of photoelastic coatings may be applied on a wide range of materials with simple or complex shapes, such as metals, composites, concrete and more. The advantage of reflection photoelasticity is a fact that it allows identify critical locations, define areas with low and high stress levels, accurately measure stress peaks and determine stress concentrations in the surrounding of holes, notches, champers and others potential failure areas.

The experimental measurement procedure consisted in applying an optically sensitive coating PS-1D with thickness $0.5 \mathrm{~mm}$. Basic optical-mechanical properties of the photoelastic layer PS-1D according to Vishay are listed in Table 3. Parameters of principal stresses that occur on the analysed specimen were determined by means of reflection photoealasticity. For this purpose, was used a reflection polariscope LF-Z/2. In Fig. 14 is a slide bearer with photoelastic coating. For comparison of the results, a blind hole with a diameter of $3.2 \mathrm{~mm}$ was drilled to a depth of $2.0 \mathrm{~mm}$. Fig. 15 shows process of the drilling of a blind hole.

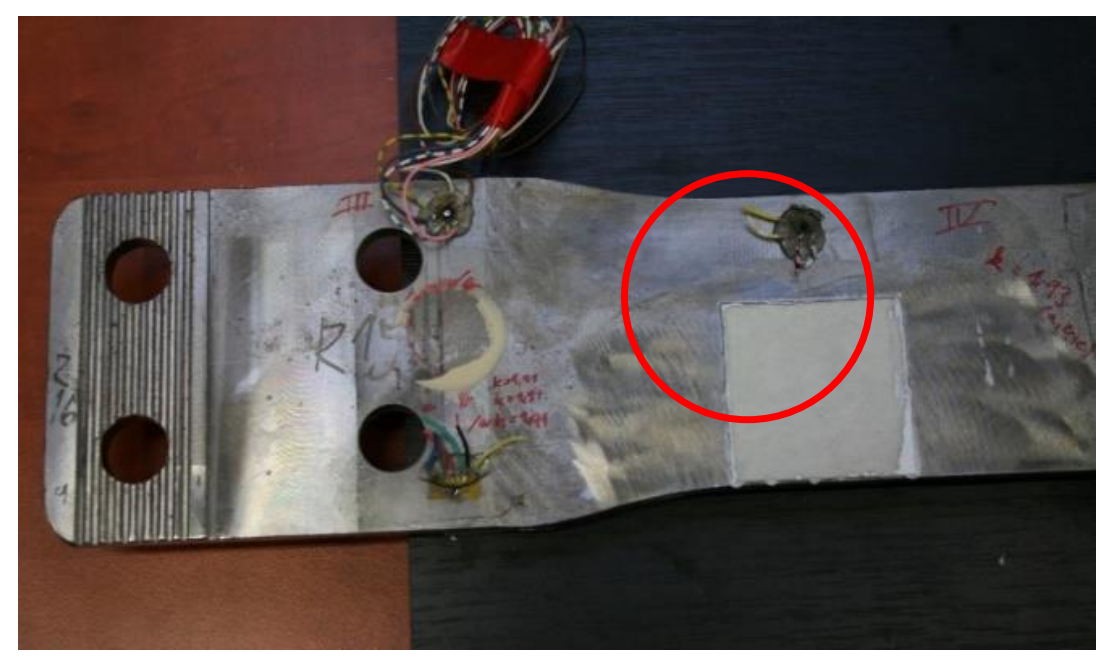

Fig. 14 Slide bearer with optical sensitive coating.

Table 3. Basic optical-mechanical properties of the photoelastic layer PS-1D.

\begin{tabular}{cc}
\hline Optical-mechanical constant $K[-]$ & 0.15 \\
Modulus of elasticity $E[\mathrm{MPa}]$ & 2500 \\
Poisson's ratio $\mu[-]$ & 0.36 \\
Optical sensitivity constant $f[-]$ & $3790.10^{-6}$ \\
\hline
\end{tabular}




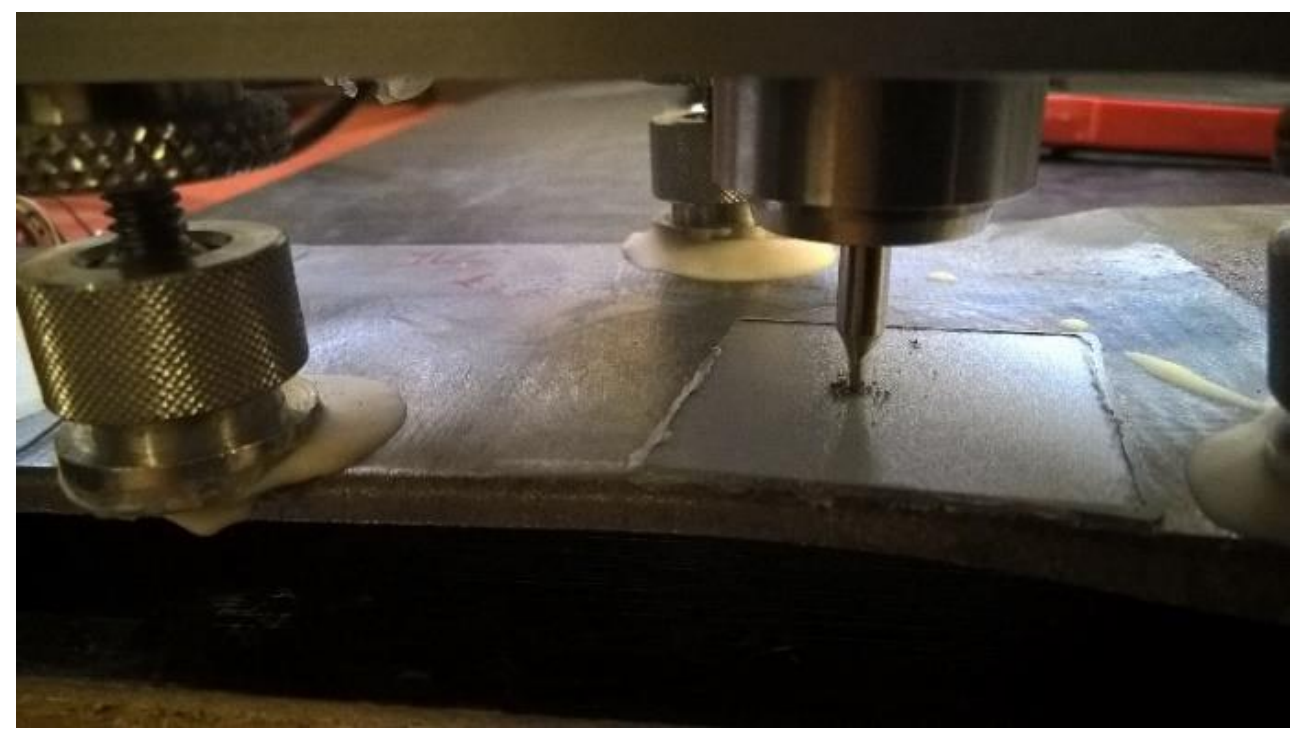

Fig. 15 Process of the drilling of a blind hole.

Analysed points 1, 2, 3 and 4 were selected around the blind hole (see Fig. 16).

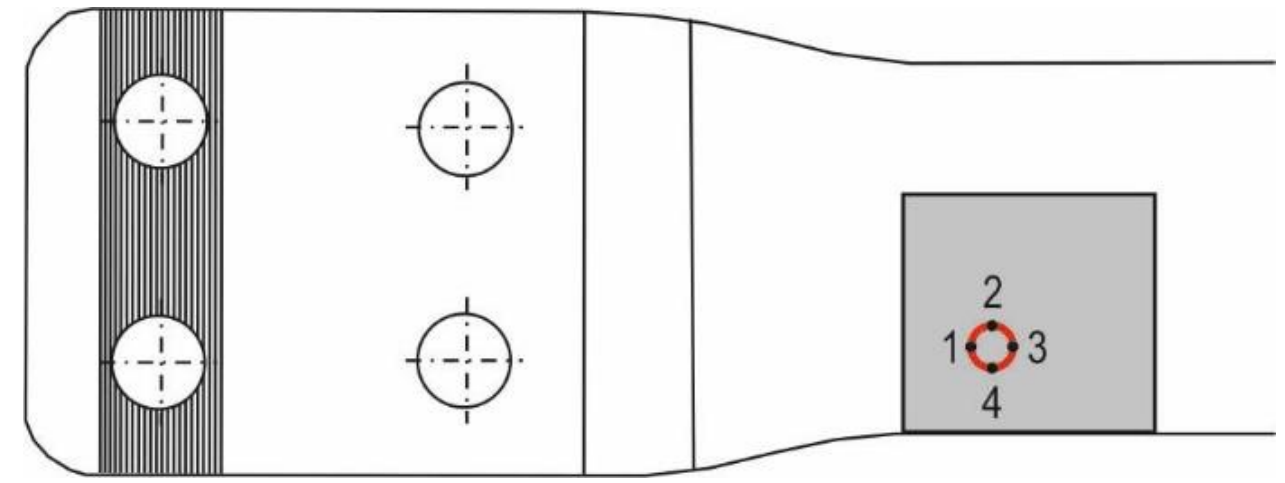

Fig. 16 Location of the examined points at the edge of the blind hole.

For the setting of compensator location, it is necessary to know the direction of principal stresses in investigated point. As the principal stress on the edge of model is equal to zero, the non-zero principal stresses on the model edge are in direction of the normal to the model contour. For this reason, the location of compensator in investigated point is known. The process of experimental identification of fringe order using compensator model 832 is depicted in Fig. 17.

According to the orientation of the compensator at the examined point at the edge of the blind hole, it is possible to determine whether it is a tensile or compression stress. At the edge of the hole, one of the main stresses is equal to zero and therefore non-zero tension is determined by the relationship [20]

$$
\sigma=\frac{E}{1+\mu} \cdot N \cdot f
$$

where $N$ - fringe order value, $f$-optical sensitivity constant, $\mu$ - Poisson ratio, $E$ - Young's modulus. 


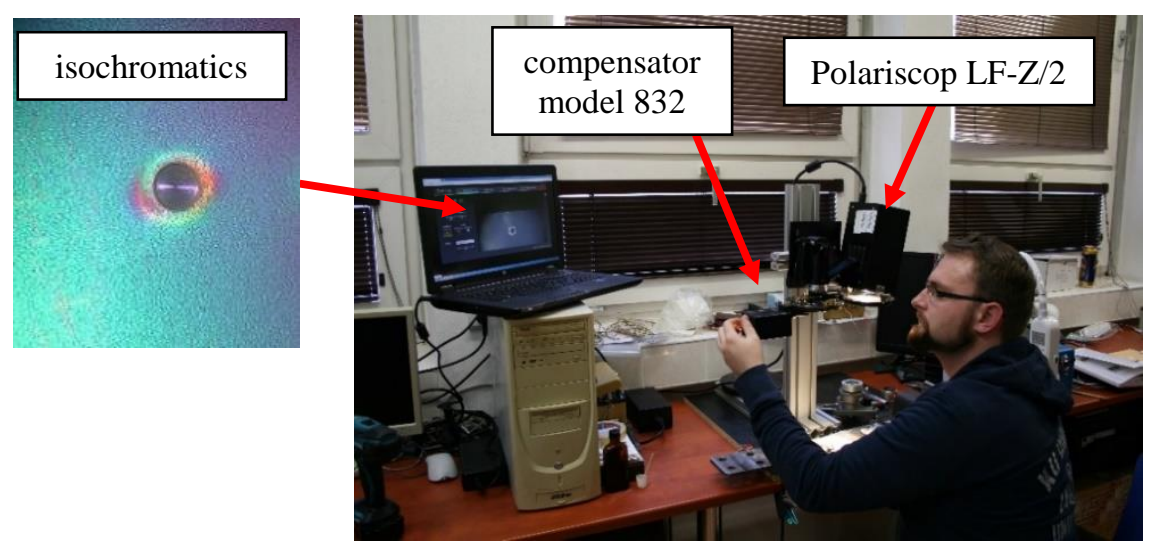

Fig. 17 Process of measuring fringe order value by null-balance compensator

The values of the stresses at the points examined (Fig. 16) for the depth of the blind hole $2.0 \mathrm{~mm}$ determined according to the equation (1) are given in the Table 4. Based on the results obtained by the Photostress method, it is possible to conclude that in the edge of the drilled hole the pressure stress levels are about $300 \mathrm{MPa}$.

Table 4. Values of the principal stresses at analysed points.

\begin{tabular}{cccc}
\hline $\begin{array}{c}\text { Analysed } \\
\text { point }\end{array}$ & $\begin{array}{c}\text { Orientation of compensator } \\
\text { to edge of hole }\end{array}$ & $\begin{array}{c}\text { Fringe order value } \\
\boldsymbol{N}[-]\end{array}$ & $\begin{array}{c}\text { Normal stress } \\
\boldsymbol{\sigma} 3\end{array}[\mathrm{MPa}]$ \\
1 & $\perp$ & 0.45 & -275.50 \\
2 & $\perp$ & 0.52 & -318.36 \\
3 & $\perp$ & 0.47 & -287.75 \\
4 & $\perp$ & 0.51 & -312.24 \\
\hline
\end{tabular}

When quantifying residual stresses by the drilling method, the hole should be drilled in several steps, either with the same increment (in case of uniform strain distribution over the sample thickness) or the ASTM E837-13a defined increment for uneven stress distribution. At present, the authors are testing the prototype of their own device allowing the evaluation of the released proportional deformations in the individual drilling steps using the Photostress method (Fig. 18).
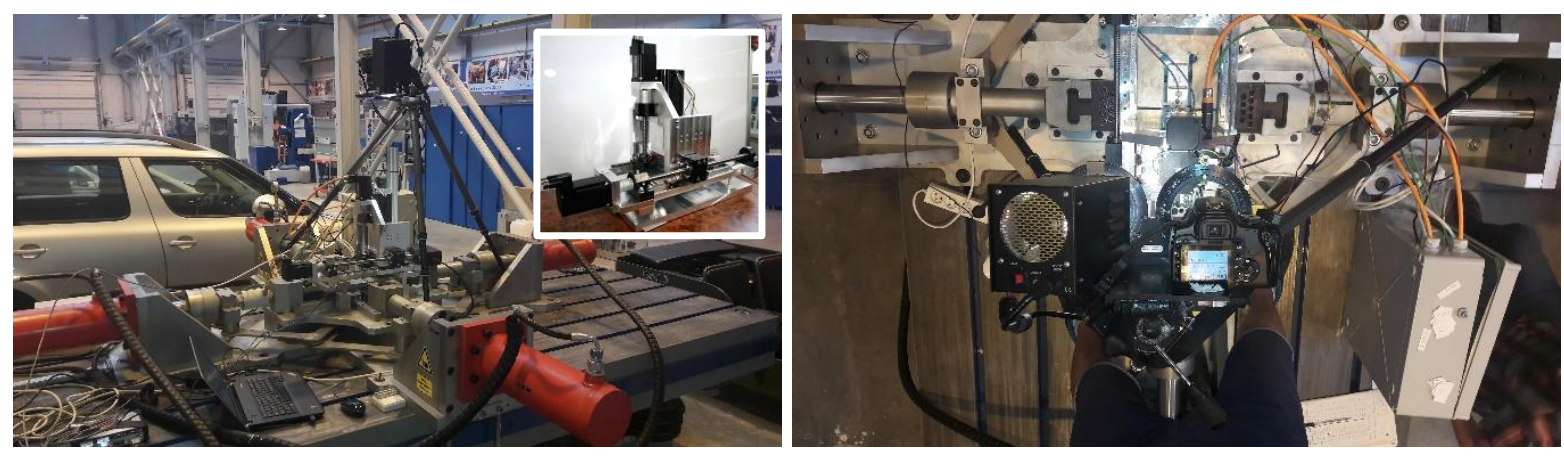

Fig. 18 Using the Photostress method for quantification of residual stress in accordance with standard ASTM E837-13a. 


\section{CONCLUSION}

In the paper, the authors assessed the influence of the residual stresses on the failure of the glider anchor belt made of 51CrV4 QT steel. It is a high-strength steel designed for highly stressed machine parts and characterized by high values of fatigue limit at alternating stress.

The anchor belt was damaged after its structural modification implemented in order to avoid undesirable horizontal displacement. As Fig. 5 shows, the fracture occurred in the area of the front pair of bolt holes and the newly formed grooves (variant 1). The anchor belt with grooves formed only in the area of the rear pair of bolt holes (variant 2) was not damaged even after the end of the dynamic (operational) test.

Given the fact that in the production of anchor belt residual stresses are formed in the surface layers due to the technology of production or treatment, it was necessary to assess their impact on the possible origin of the failure. Residual stresses were determined by the hole drilling method using SINT MTS 3000 system. The identification of the experimental measurement sites was performed on the basis of numerical modelling by the finite element method. The experimental measurement was carried out on two anchoring belts - one of these was unused and the second one was operated $\left(9.10^{6}\right.$ cycles $)$, while at each anchorage belt the measurement was implement in two places determined not only on the basis of the numerical modelling, but also taking into account the possibility of applying strain gauges.

For the evaluation, Restan software was used in accordance with ASTM E 837-13a standard. The values of the measured residual stresses in each location (I, II, III, IV) were negative, which correlates well with the fact that the analysed anchor belts were made by forging and then blasted with steel grit.

For the verification of the results achieved, the Photostress optical method was used. Based on experimental measurement carried out in the site $\mathrm{V}$, it was shown that, around blind hole with $3.2 \mathrm{~mm}$ diameter at a depth of $2,0 \mathrm{~mm}$, there were identified isochromatic fringes documenting low stress gradient. The values of principal stresses in the analysed points 1,2,3,4 (Fig. 16) reached negative values (Tab. 4) corresponding to the values determined by the drilling method.

The fact that the residual stress values determined in the examined sites were not identical is documented by the fact that the residual stresses in the entire anchor belt are not constant and their sizes and directions are different in individual sites. What is important is that they achieved only negative values in every measured place. The fatigue limit of the anchor belt material reaches $600 \mathrm{MPa}$. From the point of view of the dynamic loading of the anchor belt, the measured residual stress values can be considered favourable, as the pressure stresses favourably affect the fatigue limit.

\section{ACKNOWLEDGEMENT}

This paper was supported by project APVV 15-0435, project VEGA No. 1/0751/16 and project ITMS 26220220182 supported by the Research \& Development Operational Programmed funded by the ERDF.

\section{REFERENCES}

[1] available on the internet "bogie"

[2] Búry, M. "Residual Stress in Elastic Side Friction Block”, TUKE, p. 68, 2018.

[3] Fürbacher, I. "Lexicon of technical materials", Praha: Dashöfer, 1998 - 2006. ISBN 8086229-02-5. 
[4] Schajer, G. S. "Practical residual stress measurement methods", John Wiley \& Sons Ltd, The Atrium, Southern Gate, Chichester, West Sussex, PO19 8SQ, United Kingdom, 2013. ISBN 978-1-118-34237-4.

[5] Trebuňa, F., Šimčák, F. “Quantification of residual stresses by tensometry” (in Slovak), TUKE, p. 134, 2005.

[6] Beghini, M., Bertini, L., Giri, A., Santus, C., Valentini, E. "Measuring residual stress in finite thickness plates using the hole-drilling method", Journal of Strain Analysis for Engineering Design 54 (1), pp. 65 - 75, 2019. DOI: 10.1177/0309324718821832

[7] Barsanti, M., Beghini, M., Bertini, L., Monelli, B. D., Santus, C. "First-order correction to counter the effect of eccentricity on the hole-drilling integral method with strain-gage rosettes", Journal of Strain Analysis for Engineering Design 51 (6), pp. 431 - 443, 2016. DOI: $10.1177 / 0309324716649529$

[8] ASTM E837-13a, "Standard Test Method for Determining Residual Stresses by the HoleDrilling Strain-Gage Method", American Society for Testing and Materials, 2013.

[9] Valentini, E., Bertelli, L., Benincasa, A. "Improvements in the hole-drilling test method for determining residual stresses in polymeric materials", Materials Performance and Characterization 7 (4), article No. 123, 2018. DOI: 10.1520/MPC20170123

[10] www.sintechnology.com

[11] Trebuňa, F., Šimčák, F., Bocko, J., Pástor, M. “Analysis of the Causes of Casting Pedestal Failures and the Measures for Increasing Their Residual Lifetime", Engineering Failure Analysis 29, pp. 27 - 37, 2013.

[12] Trebuňa, F., Šimčák, F., Pástor, M., Šarga, P. "Residual stress analysis in containers for transport of radioactive materials", Applied Mechanics and Materials 732, pp. $28-31$, 2015. DOI: $10.4028 / w w w . s c i e n t i f i c . n e t / A M M .732 .28$

[13] Hagara, M., Trebuňa, F., Pástor, M., Huňady, R., Lengvarský, P. “Analysis of the aspects of residual stresses quantification performed by 3D DIC combined with standardized hole-drilling method", Measurement 137, pp. 238 - 256, 2019. DOI: 10.1016/j.measurement.2019.01.028

[14] Hagara, M., Huňady, R., Trebuňa, F. "Stress Analysis Performed in the Near Surrounding of a Small Hole by a Digital Image Correlation Method", Acta Mechanica Slovaca 18 (3 -4), pp. $74-81,2014$.

[15] Pástor, M., Trebuňa, F. "Application of Transmission Photoelasticimetry for Stress Concentration Analyses in Construction Supporting Parts", Applied Mechanics and Materials 611, pp. 443 - 449, 2014. DOI: 10.4028/www.scientific.net/AMM.611.443

[16] Lord, J. D., Penn, D., Whitehead, P. "The application of digital image correlation for measuring residual stress by incremental hole drilling", Applied Mechanics and Materials 13 - 14, pp. 65 - 73, 2008. DOI: 10.4028/www.scientific.net/AMM.13-14.65

[17] Lothhammer, L. R., Viotti M. R., Albertazzi Jr., A., Veiga C. L. N. "Residual stress measurements in steel pipes using DSPI and the hole-drilling technique", International Journal of pressure vessels and Piping 152, pp. $46-55,2017$. DOI: 10.1016/j.ijpvp.2017.05.008

[18] Paška, Z., Fojtík, F., Ferfecki, P. "Full field evaluation of the stress tensor components in 2D photoelasticity via computer software". Journal of Mechanical Engineering Strojnícky časopis 66 (2), pp. 63 - 66, 2016. DOI: 10.1515/scjme-2016-0019 
[19] Trebuňa, F., Pástor, M., Huňady, R., Frankovský, P., Hagara, M. "Optical Method in Mechanics" (in Slovak), TUKE, 2017.

[20] Frankovský, P., Ostertag, O., Delyová, I. "Distorsion of isochromatic fringes in the process of stress measurement in structural part by photoelasticimetry", Journal of Mechanical Engineering - Strojnícky časopis 68 (2), pp. 53 - 60, 2018. DOI: 10.2478/scjme-2018-0017 